\title{
Perception of foreign cigarettes and their advertising in China: a study of college students from 12 universities
}

\author{
Shu-Hong Zhu, Dewei Li, Buoling Feng, Tong Zhu, Christopher M Anderson
}

\begin{abstract}
Objective-To examine how deeply foreign cigarette advertising had penetrated the Chinese market when a new ban on cigarette advertising was enacted in February 1995.

Design-A survey using self-completion questionnaires administered in college classrooms from November 1994 to March 1995.

Settings-Eight universities and four medical schools in three Chinese cities: Beijing, Wenzhou, and Hangzhou.

Subjects-1896 college students who agreed to complete a written questionnaire. The mean age was 21.2 years; $39.5 \%$ of respondents were female.

Results-Four of the top eight cigarette brands most familiar to the respondents were foreign: Marlboro, 555, Kent, and Hilton. Advertisements for the foreign brands were much more likely to be seen than those for the domestic brands; those for Marlboro were reported most often $(29.7 \%)$, followed by $555(21.8 \%)$ and Kent (18.1\%). Among smokers, Marlboro was the most preferred foreign brand, by $44.2 \%$. The preference for Marlboro was also correlated with smokers having seen its advertisements. Most respondents, $71.8 \%$, believed that cigarette advertising should be banned.

Conclusions-The previous restrictions on cigarette advertising in China failed to prevent a large portion of the population from seeing and understanding the advertisements. Before the 1995 advertising ban took effect, strict limitations on imports of foreign cigarettes notwithstanding, certain highly advertised brands such as Marlboro achieved wide recognition and even consumer preference. Stricter restrictions are suggested as previous ones have failed to achieve their intended effects.

(Tobacco Control 1998;7:134-140)
\end{abstract}

Keywords: China, advertising, brand preferences

Introduction

China currently has 320 million smokers. ${ }^{1}$ It is not surprising, therefore, that foreign tobacco companies view China as a market with a potential for high profitability. ${ }^{2-7}$ To capitalise on this potential, however, requires more than that the Chinese open their market to competition from foreign tobacco companies. Either smokers of Chinese cigarettes must be persuaded to switch to foreign brands, or new smokers must be found. In Western countries, direct advertising has been shown to attract existing smokers to other brands, and to recruit new smokers. ${ }^{8-14}$ Foreign tobacco companies seem to have taken the same approach in China.

The Chinese market for cigarettes differs from its American counterpart, however, in that Chinese cigarette makers historically have enjoyed a government monopoly and a closed market, and have not advertised their products. The practice of advertising commercial products has become common only with the moves in recent years toward a more market-driven economy. ${ }^{15-17}$ The near absence of past domestic advertising in China has allowed foreign tobacco companies to employ their marketing expertise to great effect, as has been done in many other Asian countries. ${ }^{18-20}$

Concerned that the prevalence of smoking increases with advertising, the Chinese government has introduced curbs on cigarette advertisements. ${ }^{21}$ In January 1992, the People's Congress began prohibiting advertisements that directly mention cigarettes or that portray smoking, although cigarette companies could still display the brand names of their products in advertisements, at sponsored sporting events, and on television and radio programmes. ${ }^{22}$ Philip Morris, for example, has sponsored a national radio programme called American Music Hour and a national soccer league, which have helped to familiarise the Chinese public with the Marlboro name and images of "Marlboro country". ${ }^{23-25}$ Stricter legislation was enacted in February 1995 prohibiting all commercial advertising of cigarettes in public places. $^{26}$ However, advertisements remained on display in many cities after the ban was introduced. Moreover, the ban does not address the issue of whether tobacco companies may continue to sponsor events and programmes.

This study, which was conducted around the time the 1995 ban was enacted, addresses the question of how deeply the advertisement of foreign cigarettes has penetrated the Chinese market. With trade restrictions still in place, current sales of foreign cigarettes in China are limited. But as policy makers debate the possibility of opening China's market further to foreign tobacco, the question of how much of a "toe hold" foreign cigarette manufacturers already have in the Chinese market is of great 
Table 1 Familiar brands, by smoking status and gender

\begin{tabular}{|c|c|c|c|c|c|c|}
\hline \multirow[b]{2}{*}{ Brands } & \multirow[b]{2}{*}{$\begin{array}{l}\text { Overall } \\
(n=1896) \\
\%(95 \% C I)\end{array}$} & \multicolumn{3}{|l|}{ Smoking status } & \multicolumn{2}{|l|}{ Gender } \\
\hline & & $\begin{array}{l}\text { Never smoked } \\
(n=799) \\
\%(95 \% C I)\end{array}$ & $\begin{array}{l}\text { Previously smoked } \\
(n=490) \\
\%(95 \% C I)\end{array}$ & $\begin{array}{l}\text { Current smoker } \\
(n=536) \\
\%(95 \% \text { CI })\end{array}$ & $\begin{array}{l}\text { Male smoker } \\
(n=1089) \\
\%(95 \% C I)\end{array}$ & $\begin{array}{l}\text { Female smoker } \\
(n=711) \\
\%(95 \% C I)\end{array}$ \\
\hline Marlboro & $56.2(2.2)$ & $56.2(3.4)$ & $55.9(4.4)$ & $58.8(4.2)$ & $55.3(3.0)$ & $58.5(3.6)$ \\
\hline Hongtasan & $55.4(2.2)$ & $52.8(3.5)$ & $57.1(4.4)$ & $59.1(4.2)$ & $55.7(3.0)$ & $54.7(3.7)$ \\
\hline Zhonghua & $51.3(2.3)$ & $52.2(3.5)$ & $53.1(4.4)$ & $49.3(4.2)$ & $51.5(3.0)$ & $51.1(3.7)$ \\
\hline Yunyan & $42.2(2.3)$ & $42.4(3.4)$ & $51.4(4.4)$ & $50.4(4.2)$ & $48.7(3.0)$ & $45.6(3.7)$ \\
\hline 555 & $36.7(2.2)$ & $34.4(3.3)$ & $35.5(4.2)$ & $41.8(4.2)$ & $37.8(2.9)$ & $34.7(3.5)$ \\
\hline Kent & $33.2(2.1)$ & $32.4(3.2)$ & $31.0(4.1)$ & $35.8(4.1)$ & $34.3(2.8)$ & $32.5(3.4)$ \\
\hline Ashima & $27.7(2.0)$ & $31.7(3.2)$ & $26.3(3.9)$ & $22.8(3.5)$ & $23.6(2.5)$ & $34.3(3.5)$ \\
\hline Hilton & $23.0(1.9)$ & $19.4(2.7)$ & $23.5(3.8)$ & $30.2(3.9)$ & $24.6(2.6)$ & $19.7(2.9)$ \\
\hline
\end{tabular}

$\mathrm{CI}=$ Confidence intervals.

The overall sample size is greater than the sum of the sample sizes of the subcategories because some respondents did not answer the questions concerning smoking status or gender.

interest, particularly among those who work in tobacco control. This study provides some quantitative information about this question.

We present data from surveys of college students in three Chinese cities on their familiarity with foreign cigarette brands, their awareness of advertising for those brands, and their attitudes toward cigarette advertisements. Several well-established domestic brands are used as a benchmark against which the penetration of foreign brands can be assessed. The knowledge and attitudes of smokers are compared with those of non-smokers, and evidence relating advertising to brand preference is provided.

\section{Methods}

Twelve schools in three Chinese cities were selected for the survey. In Beijing, six out of 64 regular colleges and two of four medical schools were selected. Although a formal multistage sampling technique was not used, attempts were made to recruit students not only from different colleges but also from different school years in each college. In Wenzhou, a small but cosmopolitan city in coastal Southern China, both of the city's four-year colleges and its only medical school were selected. In Hangzhou, another southern city in the same province as Wenzhou, one of two medical schools was selected.

For this study, written questionnaires were distributed at the beginning or end of selected classes with the consent of the teachers. The students were assured of anonymity, and they were encouraged but not obliged to complete the questionnaire.

Of 2260 questionnaires that were distributed, 1896 were returned, for a response rate of $83.9 \%$. Of those that were returned, 977 were from Beijing, 733 from Wenzhou, and 186 from Hangzhou. The distribution by school year for students who returned a questionnaire was $32.3 \%$ first year, $25.1 \%$ second year, $20.1 \%$ third year, $19.1 \%$ fourth year, and $3.3 \%$ fifth year. The breakdown by gender was $60.5 \%$ men and $39.5 \%$ women. Ages ranged from 16 to 30 years, with a mean of 21.2 (SD 1.6) years.

The survey consisted of 58 questions mainly assessing smoking status, smoking history, quitting history, knowledge about the health consequences of smoking, the perceived social desirability of smoking, familiarity with different brands of cigarettes, recollection of advertising for those brands, brand preference, and attitudes toward cigarette advertising. The survey was conducted from November 1994 to March 1995.

Cigarette brand familiarity was assessed unaided using the free recall method. The question was: "Please list six cigarette brand names that are most familiar to you (domestic or foreign)." Awareness of cigarette advertising was obtained by asking students, in three separate questions, to list three cigarette brands that they had seen in television advertisements, three in newspapers or magazines, and three on billboards or in other forms of advertising, within the previous month. Thus each student could name up to nine different brands which he or she had seen advertised in the previous month. Duplicates were not counted.

Smoking status was assessed by the question: "Are you currently smoking?" Those who answered "yes" were classified as current smokers, regardless of how many cigarettes they had smoked in the past. Those who answered "no" were considered non-smokers. The non-smokers were then further divided into never-smokers and those who had previously smoked. The term "previously smoked" is used instead of the more common term "former smoker" because many of those in this category had tried smoking but never smoked 100 cigarettes in their lifetime (100 cigarettes is the cut-off used in most surveys in the United States to differentiate between never-smokers and ever-smokers). Thus, they were not considered ever to have been a regular smoker.

Brand preference was obtained only from current smokers. In two separate questions, they were asked: "If circumstances allowed, which one of the following brands of cigarettes would you prefer?" For each of the two questions, students were instructed to mark one brand in a precoded list. The first question listed foreign brands and the second listed Chinese brands. A well-known British brand, 555, was not included in the first list, and Yunyan, a well-known domestic brand, was not included in the second. These omissions may have distorted the actual percentages of students who preferred the remaining brands. Also, because the domestic and foreign brands were listed separately, it is not possible to compare students' preferences for the two classes of 
Table 2 Familiar brands, by city and smoking status

\begin{tabular}{|c|c|c|c|c|c|c|c|c|c|}
\hline \multirow[b]{2}{*}{ Brand } & \multicolumn{3}{|l|}{ Beijing } & \multicolumn{3}{|l|}{ Hangzhou } & \multicolumn{3}{|l|}{ Wenzhou } \\
\hline & $\begin{array}{l}\text { Overall } \\
(n=977) \\
\%(95 \% C I)\end{array}$ & $\begin{array}{l}\text { Non-smoker } \\
(n=687) \\
\%(95 \% C I)\end{array}$ & $\begin{array}{l}\text { Current smoker } \\
(n=290) \\
\%(95 \% C I)\end{array}$ & $\begin{array}{l}\text { Overall } \\
(n=186) \\
\%(95 \% C I)\end{array}$ & $\begin{array}{l}\text { Non-smoker } \\
(n=133) \\
\%(95 \% C I)\end{array}$ & $\begin{array}{l}\text { Current smoker } \\
(n=53) \\
\%(95 \% C I)\end{array}$ & $\begin{array}{l}\text { Overall } \\
(n=733) \\
\%(95 \% C I)\end{array}$ & $\begin{array}{l}\text { Non-smoker } \\
(n=540) \\
\%(95 \% C I)\end{array}$ & $\begin{array}{l}\text { Current smoker } \\
(n=193) \\
\%(95 \% C I)\end{array}$ \\
\hline Marlboro & $55.9(3.1)$ & $54.7(3.7)$ & $58.6(5.7)$ & $45.7(7.2)$ & $46.6(8.5)$ & $43.4(13.3)$ & $59.4(3.6)$ & $58.0(4.2)$ & $63.2(6.8)$ \\
\hline 555 & $34.0(3.0)$ & $33.9(3.5)$ & $34.1(5.5)$ & $27.4(6.4)$ & $24.8(7.3)$ & $34.0(12.8)$ & $42.7(3.6)$ & $38.2(4.1)$ & $55.4(7.0)$ \\
\hline Kent & $28.1(2.8)$ & 28.1 (3.4) & $27.9(5.2)$ & $37.1(6.9)$ & $37.6(8.2)$ & $35.9(12.9)$ & $39.0(3.5)$ & $35.9(4.0)$ & $47.7(7.0)$ \\
\hline Hilton & $43.0(3.1)$ & $38.0(3.6)$ & $54.8(5.7)$ & $2.2(2.1)$ & $3.0(2.9)$ & 0.0 & $1.8(1.0)$ & $1.9(1.1)$ & $1.6(1.7)$ \\
\hline Hongtasan & $56.0(3.1)$ & $56.2(3.7)$ & $55.5(5.7)$ & $61.8(7.0)$ & $60.2(8.3)$ & $66.0(12.8)$ & $52.9(3.6)$ & $49.4(4.2)$ & $62.7(6.8)$ \\
\hline Zhonghua & $24.5(2.7)$ & $23.9(3.2)$ & $25.9(5.0)$ & $69.4(6.6)$ & $71.4(7.7)$ & $64.2(12.9)$ & $82.5(2.8)$ & $83.3(3.1)$ & $80.3(5.6)$ \\
\hline Yunyan & $20.9(2.6)$ & $18.9(2.9)$ & $25.5(5.0)$ & $68.8(6.7)$ & $66.2(8.0)$ & 75.5 (11.6) & $76.7(3.1)$ & $75.2(3.6)$ & $80.8(5.6)$ \\
\hline Ashima & 33.7 (3.0) & $37.0(3.6)$ & $25.9(5.0)$ & $24.2(6.2)$ & $26.3(7.5)$ & $18.9(10.5)$ & $20.6(2.9)$ & 21.1 (3.4) & $19.2(5.6)$ \\
\hline
\end{tabular}

$\mathrm{CI}=$ Confidence intervals.

cigarettes. However, differences within each category-such as preference for a certain brand by recollection of advertising for that brand-were analysed.

$\chi^{2}$ tests were used for comparing proportions. In comparing brand familiarity or recollection of advertising, in which more than one response per question was elicited from each respondent, Cochran's $Q$ test, or logistic regression was used to test for marginal homogeneity. ${ }^{27}$

\section{Results}

FAMILIARITY WITH CIGARETTE BRANDS

When asked to name the six brands of cigarettes most familiar to them, respondents mentioned a total of 102 different brands. The brands that were mentioned by at least $20 \%$ of the respondents are defined as "the most familiar brands" to the group. They are listed in table 1, in order of their overall ranking. This list consists of eight brands: four foreign brands and four domestic brands. Three brands were mentioned by more than half of the respondents: Marlboro, Hongtasan, and Zhonghua. Marlboro, which was mentioned by $56.2 \%$ of the students, ranked highest. Logistic regression analysis for marginal homogeneity showed that Marlboro was significantly more likely to be named as a familiar brand than all others except Hongtasan, a domestic brand, which was mentioned by $55.4 \%$ of the students (all probability values $<0.01$ ).

Table 1 further shows that brand familiarity did not vary much by smoking status or by gender. Those who had tried smoking in the past but were not currently smoking, named the same top eight brands as did current smokers. Those who had never smoked a cigarette also named the same top eight. The

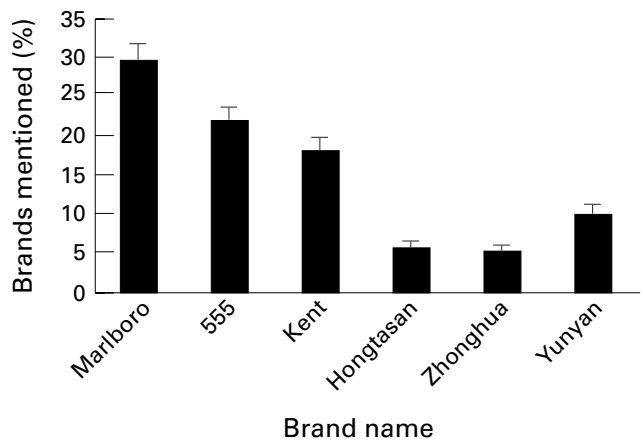

Figure 1 Six brands whose advertisements were most often seen in the month preceding the survey. percentages for the eight brands were also fairly close across smoking status. In addition, there was little gender difference in naming the most familiar cigarette brands. Female students named the same top eight brands as did male students. The rank order for female students is very similar to that for male students except between the brands Ashima and Hilton.

Table 2 shows brand familiarity by city and smoking status. Because the brand familiarity varies by city, the table arranges brand names in groups of foreign brands or domestic brands. Additionally, as those who never smoked and those who had previously smoked were very similar, they were collapsed into a single category, non-smokers, to facilitate comparison.

Overall, the most popular foreign brand, Marlboro, and the most popular domestic brand, Hongtasan, were very well known across the three cities. Familiarity with Marlboro ranged from $45.7 \%$ in Hangzhou to $59.4 \%$ in Wenzhou, and familiarity with Hongtasan ranged from $52.9 \%$ in Wenzhou to $61.8 \%$ in Hangzhou. The levels of familiarity with the other brands varied more widely among the three cities. Hilton, for example, was well known among students living in Beijing but virtually unknown in the two southern cities. The two domestic brands, Zhonghua and Yunyan, were very well known in the two southern cities although over $20 \%$ of those in Beijing also named them as most familiar brands.

Within each city, brand familiarity varied little by smoking status. For example, in Beijing, Zhonghua was familiar to $23.9 \%$ of non-smokers and to $25.9 \%$ of current smokers. In Wenzhou, the same brand was familiar to $83.3 \%$ of non-smokers and to $80.3 \%$ of current smokers. The exceptions were again for the brands Hilton and Ashima in the city of Beijing. Hilton was much more likely to be nominated by smokers than by non-smokers. The opposite is true for Ashima. For most other brands, there was no significant variation between smokers and non-smokers in each city, although there was often great variation among cities.

RECOLLECTION OF ADVERTISEMENTS

Overall, $45.9 \%$ of those surveyed named at least one brand of cigarettes which they had seen advertised in the month preceding the survey. Those brands whose advertisements 
Table 3 Brands seen in advertisements in the month preceding the survey, by smoking status and city

\begin{tabular}{|c|c|c|c|c|c|c|c|c|c|}
\hline \multirow[b]{2}{*}{ Brand } & \multicolumn{3}{|l|}{ Beijing } & \multicolumn{3}{|l|}{ Hangzhou } & \multicolumn{3}{|l|}{ Wenzhou } \\
\hline & $\begin{array}{l}\text { Overall } \\
(n=945) \\
\%(95 \% C I)\end{array}$ & $\begin{array}{l}\text { Non-smoker } \\
(n=655) \\
\%(95 \% \text { CI })\end{array}$ & $\begin{array}{l}\text { Current smoker } \\
(n=290) \\
\%(95 \% C I)\end{array}$ & $\begin{array}{l}\text { Overall } \\
(n=178) \\
\%(95 \% C I)\end{array}$ & $\begin{array}{l}\text { Non-smoker } \\
(n=125) \\
\%(95 \% C I)\end{array}$ & $\begin{array}{l}\text { Current smoker } \\
(n=53) \\
\%(95 \% C I)\end{array}$ & $\begin{array}{l}\text { Overall } \\
(n=702) \\
\%(95 \% C I)\end{array}$ & $\begin{array}{l}\text { Non-smoker } \\
(n=509) \\
\%(95 \% C I)\end{array}$ & $\begin{array}{l}\text { Current smoker } \\
(n=193) \\
\%(95 \% C I)\end{array}$ \\
\hline Marlboro & $32.9(3.0)$ & $29.6(3.5)$ & $40.3(5.6)$ & $36.5(7.1)$ & $32.0(8.2)$ & $47.2(13.4)$ & $25.2(3.2)$ & $22.2(3.6)$ & $33.2(6.6)$ \\
\hline 555 & $16.7(2.4)$ & $15.6(2.8)$ & $19.3(4.5)$ & $19.7(5.8)$ & $15.2(6.3)$ & $30.2(12) 4$. & $30.1(3.4)$ & $24.0(3.7)$ & $46.1(7.0)$ \\
\hline Kent & $15.5(2.3)$ & $13.3(2.6)$ & $20.3(4.6)$ & $25.8(6.4)$ & $20.0(7.0)$ & 39.6 (13). 2 & $20.7(3.0)$ & $18.3(3.4)$ & $26.9(6.3)$ \\
\hline Hongtasan & $5.6(1.5)$ & $5.3(1.7)$ & $6.2(2.8)$ & $7.9(4.0)$ & $8.8(5.0)$ & $5.7(6.2)$ & $4.8(1.6)$ & $6.0(2.0)$ & $2.1(2.0)$ \\
\hline Zhonghua & $1.9(0.9)$ & $2.0(1.1)$ & $1.7(1.5)$ & $10.1(4.4)$ & $11.2(5.5)$ & $7.6(7.1)$ & $8.1(2.0)$ & $8.3(2.4)$ & $7.8(3.8)$ \\
\hline Yunyan & $2.0(0.9)$ & $1.1(0.8)$ & $4.1(2.3)$ & $19.7(5.8)$ & $11.2(5.5)$ & $39.6(13.2)$ & $19.0(2.9)$ & $13.2(2.9)$ & $34.2(6.70$ \\
\hline
\end{tabular}

$\mathrm{CI}=$ Confidence intervals

were mentioned by at least $5 \%$ of the respondents are presented here.

Figure 1 shows the six advertised brands that were, on average, reported by at least $5 \%$ of the respondents. These six brands are a subset of the brands in table 1 . The ranking between these six brands, however, differs from that in table 1 . The top three brands are all foreign cigarettes. They were much more likely to have been seen in advertisements than the three domestic brands $(\mathrm{p}<0.001)$. On average, advertisements for Marlboro were seen by the greatest percentage of respondents, $29.7 \%$, significantly higher than for any other brand $(p<0.001)$. Percentages for the other two top foreign brands $(21.8 \%$ for 555 and $18.1 \%$ for Kent) were also significantly higher than those for the top three domestic brands (both probability values <0.001). The highest ranking domestic brand, Yunyan, was reported by only $10 \%$, while the other two top domestic brands were reported even less often (both probability values $<0.01)$. Advertisements for the most familiar domestic brand, Hongtasan, were reported by only $5.5 \%$ of respondents.

Table 3 shows the data on the recollection of these different advertisements by city and smoking status. Following the format of table 2, never-smokers and those who previously smoked are collapsed into non-smokers in this table. Overall, Marlboro, 555, and Kent were each reported by at least $15 \%$ of respondents across the three cities. The most advertised domestic brand, Yunyan, was seen mostly in the southern cities. There was a difference

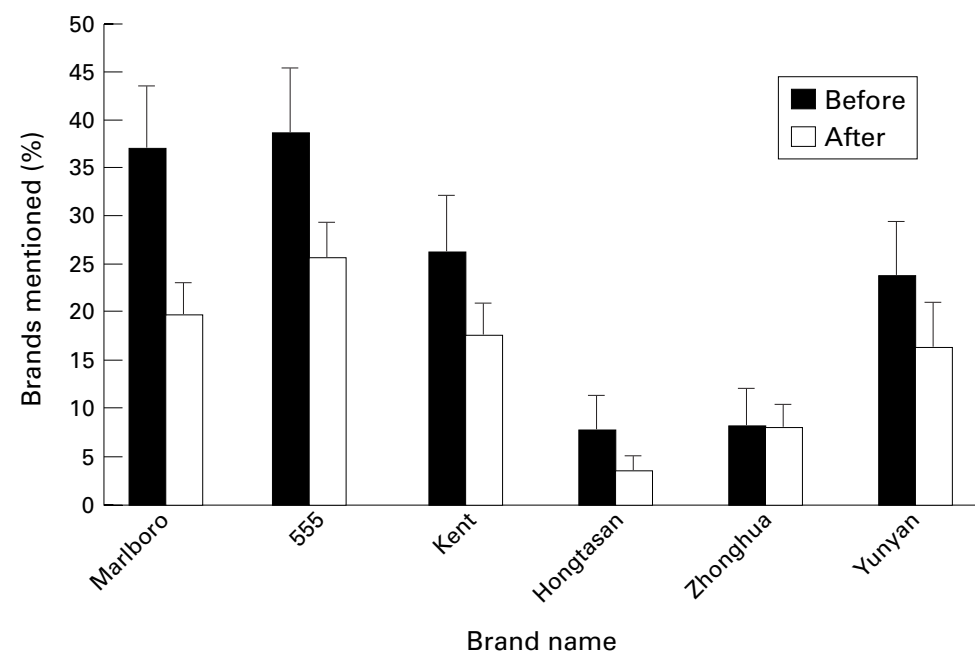

Figure 2 Six brands most often seen advertised in the previous month, before and after the ban on advertising. between smokers and non-smokers in their reporting of advertisements, but the difference was observed only for those brands reported by more than $15 \%$ of respondents: Marlboro, 555 , and Kent in all three cities, and Yunyan in Hangzhou and Wenzhou.

Figure 2 shows recollection of advertisements by time of survey, relative to the pronouncement in February 1995 banning cigarette advertising. For this analysis, only data from the city of Wenzhou were used, because all surveys in Beijing and Hangzhou were completed before the ban; in Wenzhou, 527 of the 733 students were surveyed afterward, in March 1995. Figure 2 shows that cigarette advertising in that city dropped markedly, but was still visible.

\section{BRAND PREFERENCE}

From a precoded list of foreign cigarette brands, the highest percentage of smokers, $44.2 \%$, selected Marlboro as the foreign brand they would most prefer. From a similar list of domestic brands, the highest percentage of smokers, $49.1 \%$, selected Zhonghua as the Chinese brand they would prefer the most.

A further analysis found an interesting difference between the top foreign brand, Marlboro, and the top domestic brand, Zhonghua. For Marlboro, there is a positive correlation between recollection of seeing it advertised and preference: current smokers who reported having seen a Marlboro advertisement in the previous month were significantly more likely to prefer Marlboro cigarettes, $51.5 \%$, than those who did not report having seen such an advertisement, $39.7 \%(\mathrm{p}<0.01)$. On the other hand, current smokers who reported having seen a Zhonghua advertisement in the last month were not significantly more likely to prefer Zhonghua cigarettes than those who did not report having seen such an advertisement $(50.0 \%$ vs $49.0 \%$, $\mathrm{p}=0.93$ ).

ATTITUDES TOWARD CIGARETTE ADVERTISING Most students surveyed-71.8\% - believed that cigarette advertising should be banned, although current smokers were significantly less likely to think so than both non-smoking groups (both probability values $<0.01$ ). The percentages of students advocating the ban were $60.8 \%$ of current smokers, $76.8 \%$ of those who had never smoked, and $75.7 \%$ of those who had smoked in the past but were not currently smoking. Overall, only a very small segment of students, $5.2 \%$, believed that 
cigarette advertising should be allowed. Another $23.0 \%$ of the respondents had no opinion.

\section{Discussion}

This study shows that even though trade restrictions remain in place, foreign cigarette companies have deeply penetrated the Chinese market, not yet in legal sales but certainly in terms of brand awareness and preference. Their advertisements have been seen and understood, despite the fact that starting in January 1992, the advertisements were not allowed to mention cigarettes or show smoking. There is evidence that foreign advertising so far has not only made the Chinese public very familiar with foreign cigarettes, but has influenced their brand preferences and presumably their future buying patterns, should the trade restrictions be loosened. This study confirms the concerns expressed by the international community about the future influence of Western tobacco companies in China. ${ }^{28} 29$

It is remarkable that with the restrictions on foreign cigarettes still in effect, four of the eight most familiar brands were foreign. At the time of the survey, foreign cigarette sales accounted for less than $1 \%$ of all legal sales in China. ${ }^{25}$ With minimal legitimate inventory on hand in the country, the high level of familiarity with foreign cigarettes can at least partially be attributed to advertising. Three foreign brands-Marlboro, 555, and Kent-were heavily advertised before this survey, and they are among the top eight most familiar brands.

Among the four most familiar foreign brands, only Hilton did not conduct an advertising campaign across all three cities. As a result, it was only known to those in Beijing. One explanation for the popularity of Hilton is its price; Hilton was much less expensive than all the other brands shown in table 1 . At the time of the survey, the retail price for Hilton was 5 yuan (Y) per pack. The prices for Marlboro, 555, and Kent were 10, 11, and 8Y, respectively. The prices were $12,28,8$, and $10 \mathrm{Y}$ for the brands Hongtasan, Zhonghua, Yunyan, and Ashima, respectively. In fact, Hilton was the only foreign brand that was nominated by a significantly higher percentage of smokers than of non-smokers in the city of Beijing ( $54.8 \%$ vs $38.0 \%)$. This suggests that Hilton may have achieved notoriety differently from Marlboro, 555, and Kent. The former might have gained recognition first through smokers who were more sensitive to price, while the latter relied mainly on advertisements, which could be seen by smokers and non-smokers alike.

Overall, advertising by Marlboro made the biggest impression, as $30 \%$ of the students reported having seen it in the month before the survey. Not surprisingly, Marlboro was the most familiar foreign cigarette brand. It even rivalled the most popular domestic brand, Hongtasan, not only in its overall familiarity but in its consistently high familiarity across different groupings of subjects. Like Hongtasan, Marlboro was very familiar in all three cities sampled, a distinction that no other brand achieved. This can be attributed at least in part to the sheer frequency of the Marlboro advertisments. The Marlboro advertisements may also have been more memorable or effectively placed than advertisements for other brands. Whatever the case, Marlboro, the world's leading brand of cigarettes, has already achieved notoriety among potential Chinese customers even before any large sales have been legalised.

Marlboro in China enjoys not only familiarity, but even preference over other cigarettes. Smokers in the survey considered it the best choice among foreign cigarettes, or at least among American cigarettes (the British brand 555 was not listed as an option in that question). It should be noted that the questions regarding brand preference on the survey were hypothetical: "If circumstances allowed, which one of the following cigarettes would you prefer?" Respondents did not actually have to have smoked Marlboro cigarettes to select them as their preferred brand. At any rate, Marlboro has distinguished itself as the most preferred brand. Furthermore, preference for this brand is related to advertising, inasmuch as those who reported seeing Marlboro advertisements in the month preceding the survey had a significantly stronger preference for Marlboro cigarettes than those who did not report seeing them.

In contrast, the familiarity with and the preference for the domestic brands of cigarettes, in most cases, have little to do with advertising. The two most popular brands, Hongtasan and Zhonghua, which were each nominated by more than $50 \%$ of the respondents, were seen in advertisements by only $6 \%$ and $5 \%$, respectively. These brands seem to have achieved their notoriety differently. Zhonghua, for example, may owe its popularity to a longstanding reputation as the "royal brand", so called because it was not available to average citizens for many years. Even when it was available in the market, the price was prohibitive: a pack of Zhonghua cost the same as three packs of Marlboro. Judging from the reported advertising level for Zhonghua, one might infer that the maker of this brand did not consider it necessary to put money into advertising.

One domestic brand, Yunyan, however, put out a major advertising effort in the two southern cities surveyed. The recall of its advertisements rivalled that of 555 in the city of Hangzhou and that of Kent in the city of Wenzhou. It is not clear how much its name recognition is attributable to the advertising because there are no data about the popularity of different domestic brands before the advertising began. But one thing is clear, it was very popular in the two southern cities where it was advertised. That the makers of domestic cigarettes such as Yunyan began to consider it necessary to advertise is an issue worth further investigation, because domestic cigarette brands traditionally had not used advertising to attract consumers.

This leads to the question whether advertising in the current Chinese market may confer a 
greater advantage than in the West, where the practice of advertising is much more common. The data for the domestic brands in this study show that their rate of familiarity varies more by city than by smoking status. For example, Zhonghua overall is more familiar in Wenzhou than in Beijing (table 2). The non-smokers in Wenzhou are more similar to the smokers in Wenzhou than to their non-smoking counterparts in Beijing, in terms of their familiarity with Zhonghua. The non-smokers in Wenzhou are much more familiar with Zhonghua than are the smokers in Beijing. This pattern holds true for other brands, despite the fact that there are significant differences between smokers and non-smokers in terms of who remembers seeing the advertisements. The fact that non-smokers are nearly as familiar with a product they never use as their neighbours who do use it, raises a question relating to the diffusion of information. It appears that in China, communal knowledge is a better predictor of familiarity with a given brand of cigarettes than is smoking status. These results suggest that the effects of advertising may be amplified in such a market, where information generated by cigarette advertisements is effectively channelled into a shared pool of knowledge.

If this hypothesis is substantiated, it has serious implications for tobacco control in China. It has been demonstrated in Western countries that continued exposure to cigarette advertising leads to initiation of smoking. ${ }^{11}$ Although non-smokers in China are less immediately aware of cigarette advertising than smokers, they are as familiar with the advertised brands. One group of particular concern in this regard is non-smoking Chinese women. ${ }^{30}$ Given the pattern seen elsewhere in the world, in which the development of a women's movement is accompanied first by an increase in the prevalence of smoking among women and later by an increase in smoking-related diseases among women, ${ }^{31}$ further study is needed to determine whether this pattern applies in China and to delineate the relation between the promotion of cigarettes in China and the uptake of smoking.

There are several limitations in this study. Although efforts were made to include various schools, no formal multistage random sampling was employed to select survey respondents. This limits the generalisability of the results. In addition, using a precoded list of cigarette brands in the question about brand preference limited respondents' answers. The omission of the popular foreign brand 555 and the popular domestic brand Yunyan from this list may have biased the assessment of brand preferences. Lastly, we were unable to obtain data on the advertising expenditures of the foreign cigarette companies, which would have allowed us to check the recall of advertising against the actual intensity of advertising.

These limitations notwithstanding, this study is a first attempt at an empirical assessment of foreign cigarette advertising and its impact in China. An immediate conclusion to be drawn from this study, relevant to future efforts in tobacco control in China, is that despite the 1992 requirement that cigarette advertising be less explicit, the altered advertisements were still successful in conveying their message to the public. In fact, $45.9 \%$ of the students surveyed reported having seen advertisements in the previous month that they could identify with particular brands of cigarettes.

The new law completely banning advertising in public places is a significant step toward reducing the promotion of cigarettes. However, such advertisements continued to be displayed long after its enactment. ${ }^{32}$ Furthermore, tobacco companies find other ways to advertise. Most notable are Marlboro World of Soccer, a popular sports television programme, and the 555 Hong Kong to Beijing motor rally, a long-distance auto race televised nationwide. ${ }^{33}$ There are many other creative promotional activities. For example, on the fifth day of the fifth month of the Chinese calendar, the Chinese traditionally hold the dragon boat festival. At $5 \mathrm{pm}$ on this day, the British manufacturer of the 555 brand of cigarettes sponsored boat races for this festival. The effects of such promotional activities have yet to be investigated in China, although the results from this study, showing that smokers and non-smokers share knowledge about cigarettes almost equally, suggest that sponsorship of such communal activities may be particularly effective in fostering brand recognition.

If the intention of the current ban is to put an end to the promotion of cigarettes, further restrictions on tobacco industry sponsorship of sports and other public events are needed. It is fortunate that there seems to be public sentiment in support of such restrictions, as most students surveyed before the new law took effect supported banning cigarette advertising.

The authors wish to thank Dr John Pierce for suggesting this topic of research, Mr Bradley Rosbrook for statistical assistance, and Drs Judith Mackay and Bao-Ping Zhu for their helpful comments on an earlier draft of this paper.

1 Yang G, Fan L, Huang Z, et al. Smoking and health in China: 1996 national prevalence survey of smoking pattern. China Science and Technology Press: Beijing, 1997.

2 Connolly GN. Worldwide expansion of transnational tobacco industry. F Natl Cancer Inst 1992;12:29-35.

3 Mufson S. Cigarette salesmen target China. Washington Post 1995 Jul 2.

4 American Medical Association Council on Scientific Affairs. The worldwide smoking epidemic: tobacco trade, use, and control. $\mathscr{f} A M A$ 1990;263:3312-18.

5 Teft S. Tobacco companies see huge market in China. Christian Science Monitor 1994 May:6.

6 Shenon P. Asia's having one huge nicotine fit. New York Times 1994 May 15:E1,16.

7 Mackay J. The tobacco problem: commercial profit versus health-the conflict of interests in developing countries. Prev Med 1994;23:535-8.

8 Tennant RB. The American cigarette industry. A study in economic analysis and public policy. New Haven, Connectieconomic analysis and public policy.

9 US Centers for Disease Control and Prevention. Changes in the cigarette brand preferences of adolescent smokersUnited States, 1989-1993. MMWR 1994;43:577-81.

10 Pierce JP, Lee L, Gilpin EA. Smoking initiation by adolescent girls, 1944 through 1988: an association with targeted advertising. FAMA 1994;271:608-11.

11 Pierce JP, Gilpin EA. A historical analysis of tobacco marketing and the uptake of smoking in the United States: 1890-1977. Health Psychol 1995;14:500-8.

12 Goddard E. Why children start smoking: an enquiry carried out by Social Survey Division of OPCS on behalf of the Department of Health. Office of Population Censuses and Surveys, Social Survey Division, London: HMSO, 1990. 
13 Alexander HM, Callcot R, Dobson AJ, et al. Cigarette smoking and drug use in schoolchildren: IV-factors associated with changes in smoking behaviour. Int $\mathcal{F}$ Epidemiol 1983;12:59-66.

14 Armstrong BK, de Klerk NH, Shean RE, et al. Influence of education and advertising on the uptake of smoking by children. Med f A ust 1990;152:117-24.

15 Ho SC, Chan CF. Advertising in China: looking back and looking forward. Int $\mathcal{F}$ Advertising 1986;5:307-16.

16 Curry L. China. Advertising Age 1988;59:110.

17 Hong J. The resurrection of advertising in China: developments, problems, and trends. Asian Survey 1994;34:32642.

18 Chen TTL, Winder AE. The opium wars revisited as US forces tobacco exports in Asia. Am $\mathcal{f}$ Public Health, 1990;80:659-62.

19 Stebbins KR. Tobacco, politics and economics: implications for global health. Soc Sci Med 1991;33:1317-27.

20 McKerrow R. Going up in smoke: US tobacco companies are targeting Asian smokers, says Richard McKerrow. New Statesman Society 1992;5:16-17.

21 Weng XZ. Anti-smoking campaign in China. Chin Med $\mathcal{f}$ 1990;103:875-8

22 Mackay J. China's landmark tobacco law. World Health Forum 1992;13:205.

23 Sesser S. Opium war redux. New Yorker 1993;69:78-89.
24 Lou L. Marlboro helps China promote motor sports. Beijing Rev 1992 April 13:19.

25 Brooks J. American cigarettes have become a status symbol Brooks J. American cigarettes have become a status symbol
in smoke-saturated China. Can Med Assoc f 1995; 152:1512-13.

26 Brauchli MW. Ad ban in China makes tobacco tricky business. Wall Street fournal 1994 Dec 28:B1,B7.

27 Agresti A. Categorical data analysis. John Wiley: New York, 1986

28 Davis RM. Slowing the march of the Marlboro man. BMf 1994;309:889-90

29 Mackay J. China's tobacco wars. Multinational Monitor 1992;13:9-12.

30 Peto R, Chen Z, Boreham J. Tobacco-the growing epidemic in China. fAMA 1996;275:1683-4.

31 US Department of Health and Human Services. Reducing the health consequences of smoking: 25 years of progress. A
report of the Surgeon General, 1989. Rockville, Maryland: Public Health Service, Centers for Disease Control, Office on Smoking and Health, 1989. (DHHS Publication No (CDC) 89-8411.)

32 Beijing orders crackdown on foreign-cigarette ads. Wall Street fournal 1997 Jul 31:B10.

33 Keenan F. Staying in the game- tobacco firms in China live with sponsorship limits. Far Eastern Economic Review 1995;158:67.

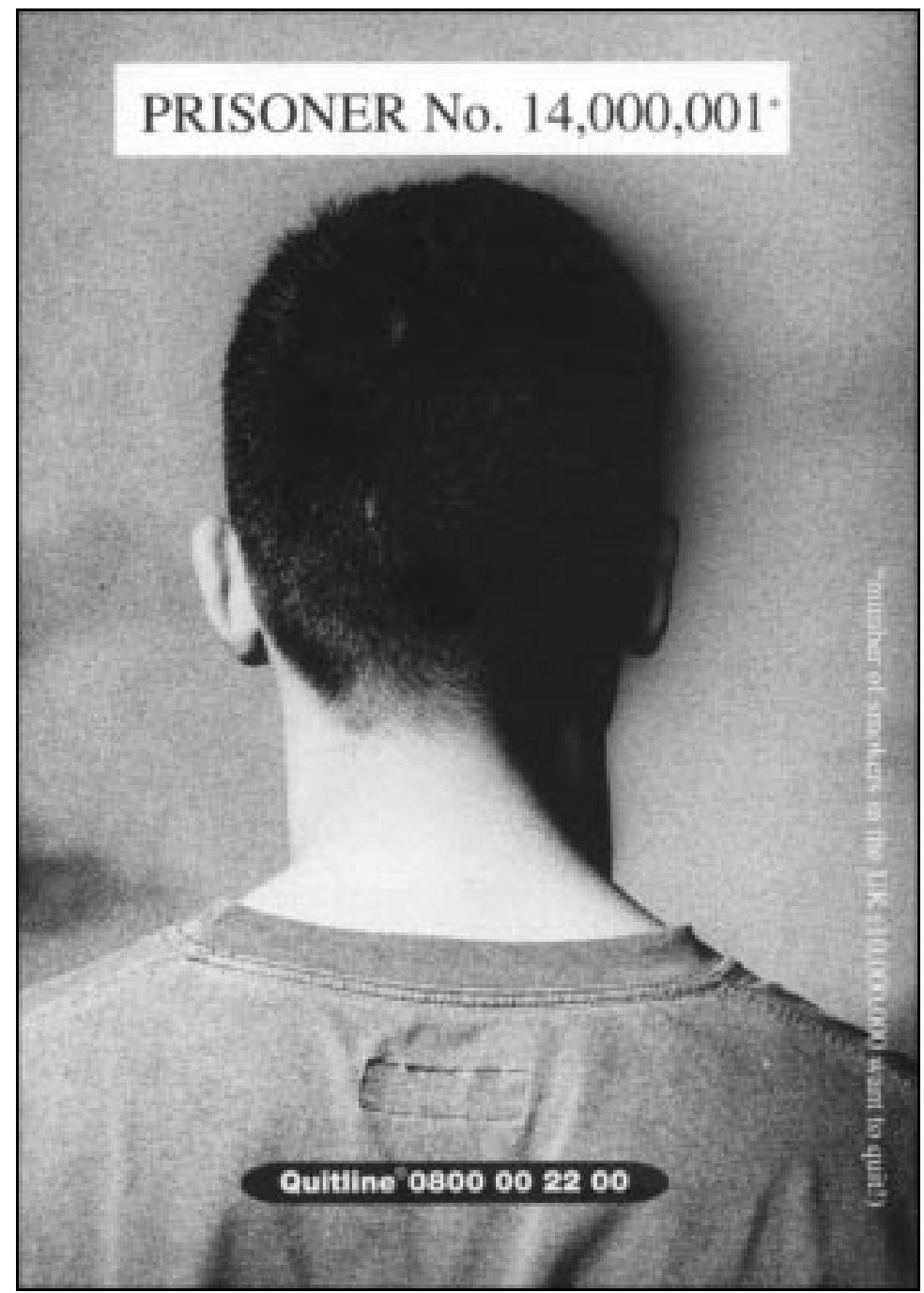

A poster from the National Freephone (toll free) Quitline Service in the United Kingdom as displayed on the Smoke Free Birmingham web site (go to <http://

www.smokefree.org.uk/>, then click on "Gallery"). The footnote, referring to the asterisk in the title, reads " number of smokers in the UK (10,000,000 want to quit!)". 